\title{
Integrating simulation in a BSN leadership and management course
}

\author{
Shannon Bright Smith \\ College of Nursing, Medical University of South Carolina, Charleston, USA; Adjunct Faculty, College of Nursing, University \\ of Phoenix, Phoenix, AZ
}

Correspondence: Shannon Bright Smith. Address: 827 Hoss Road, Charleston, SC 29414, USA. Email: smithsh@musc.edu.

Received: November 30, 2012

Accepted: March 26, $2013 \quad$ Online Published: May 15, 2013

DOI : 10.5430/jnep.v3n11p121

URL: http://dx.doi.org/10.5430/jnep.v3n11p121

\begin{abstract}
Simulation is becoming an increasingly popular learning strategy for many nursing courses in undergraduate nursing programs to help students learn critical thinking skills in patient care. Yet, many programs do not utilize simulation in Nursing Leadership and Management courses. This article reviews the literature that supports the use of simulation in BSN Leadership and Management courses and proposes an education plan for integration of simulation into the course. Learning theories and relevant pedagogy are discussed and four leadership simulation scenarios that aid faculty in leading the learners to learning are presented as a guide for implementation.
\end{abstract}

\section{Key words}

Simulation, Leadership, BSN, Pedagogy, Learning theories

\section{Introduction and background}

Simulation is something that many of us did as children and is reminiscent of the old saying "everything I need to know I learned in kindergarten." We observed our parents, older siblings, and grandparents go through their day and desired to be like them. We played dress up and each chose the person he or she longed to be like and emulated with theatrics worthy of the big screen. We often wanted to be the leader (mother) but seldom the follower (child). We wanted to tell others how to manage their time saying, "Make your bed and then you can go play." Although, simulation in this childhood reflection is quite simplistic, it accomplished the goal of learning to be who we wanted to be. Simulation in the Bachelor of Science (BSN) in Nursing Leadership and Management course can be equally effective in helping professional nursing students learn to demonstrate leadership attributes ${ }^{[1]}$.

Simulation can be a valuable tool in helping nursing leadership students attain critical attributes recommended by professional nursing organizations. The American Association of Colleges of Nursing (AACN) has reported essential knowledge that BSN students need to enter professional nursing ${ }^{[2]}$. Additionally the National Council of State Boards of Nursing (NCSBN) published NCLEX test plan delineates areas in which students will be tested on NCLEX ${ }^{[3]}$. The National League for Nursing offers resources to help faculty provide appropriate pedagogy to aid in student preparation for safe nursing practice ${ }^{[4]}$. Among them is a Simulation and Technology page that offers up-to-date information on the latest simulation innovations. The AACN's Essentials of Baccalaureate Education for Professional Nursing Practice 
purports that the Essentials document is designed to transform baccalaureate nursing programs into the 21st century ${ }^{[2]}$. Its purpose is to aid faculty's ability to develop coursework that includes the competencies that nursing students need to function as professional nurses in current and future health care environments. Additionally, the Institute of Medicine's Future of Nursing Report says that nursing education should include "competencies necessary for continuous improvement of the quality and safety of health care systems — patient-centered care, teamwork and collaboration, evidence-based practice, quality improvement, safety, and informatics” ${ }^{[5]}$. Nursing Leadership and Management courses should include student professional development emphasized in the document ${ }^{[2]}$. Faculty should seek to develop their students' ability to demonstrate effective communication and collaboration, leadership for quality care and patient safety, and translate current evidence into daily practice. Teaching and learning strategies in Nursing Leadership and Management courses should reflect important topics in nursing education. To accomplish this fete, simulation content for nursing leadership and management should include scenarios in patient safety, cultural competence, technology and informatics, interprofessional education, and critical thinking ${ }^{[6]}$. Other topics relevant to nursing leadership that should be included in a student's simulated learning experience include professionalism, delegation, communication, and teamwork and collaboration.

Simulation has been proven effective in clinical nursing courses and should be implemented consistently in Leadership and Nursing Management courses, as well. It allows faculty to interact with a variety of student learning styles in a safe environment without risking harm to patients in the clinical setting. Unlike actual clinical situations, faculty has the ability to alter the outcome of the scenario to let students experience potential benefits, complications, and/or negative impact of critical decisions. These interactions help students begin to learn and explore how it feels to be a nurse and be responsible for patient outcomes.

Clinical practice site availability and practice environments are two other reasons that simulation is a worthy alternative for preparing nursing students. Most clinical sites are currently utilized for clinical courses. It would be difficult to relegate already slim resources to yet another course that is not traditionally seen as a clinical course. Nursing workload and patient acuity makes stopping care to clarify content or provide additional student teaching close to impossible. Furthermore, such an action in the clinical setting could easily place a patient's safety at risk. The health care needs of the patient must always take priority over educating students. Simulation, however, provides for deliberate opportunities to stop, reflect, teach, and enhance student learning in a more flexible environment.

Finally, traditional modes of learning focus on the acquisition of knowledge and skills; however, simulated experiences focus on integration of learning into higher-level functions such as application, synthesis and critical thinking. Simulation also offers an environment where collaboration can be practiced with these higher-level functions of learning. It is real world nursing in a controllable, safe environment that could not be achieved in the clinical setting without potential risk of errors or harm to patients.

To properly integrate simulation into a nursing leadership course, faculty must incorporate the pedagogy of simulation; consider evidence surrounding the topic; and use evidence-based resources. To aid faculty in this innovative undertaking, this paper reviews the literature and discusses the pedagogy of simulation, and offers a proposed simulation education plan. The paper concludes with a call for additional research and implications to nursing education. It is important that faculty in BSN Leadership and Management courses assess students' learning needs, readiness to learn, and learning styles prior to program implementation. Scenarios presented are a starting point and should be tailored to student-specific needs.

\section{Literature review}

A comprehensive search of the literature was conducted using Ovid, MEDLINE, CINAHL, and PubMed databases. Key terms used in this search included leadership, simulation, nursing, nursing student, and senior. The search resulted in a total of 324 articles. The abstracts were reviewed for content and 74 articles were kept for further review. A total of 13 articles met the inclusion criteria of having been published between the years of 2007 and 2012, focused on interventions 
or observation of nursing students in leadership course, and in the English language. One study was completed in Ireland. The remaining articles were based in the United States.

The general conclusion supported by nursing literature is the need for faculty to combine sound teaching principles and theory with creative strategies to meet 21 st century nursing student needs ${ }^{[2]}$. There were three overarching themes noted in the literature review: Simulation in nursing leadership courses 1) promotes patient safety and decreased errors that could

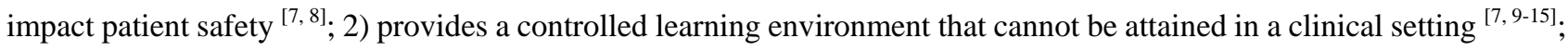
and 3) increases student confidence in decision making, critical thinking, and an overall sense of their role as a nurse ${ }^{[10,15-18]}$.

Safe and effective care environment accounts for $26 \%-38 \%$ of the NCLEX-RN exam ${ }^{[3]}$. Students must be prepared to successfully negotiate this national certification exam. Students were not as prepared as they thought ${ }^{[16]}$. In another study to determine self-efficacy of senior baccalaureate nursing students, nursing students were "unable to recall previously acquired nursing knowledge, process critical patient changing events," and perform appropriate nursing actions ${ }^{[16]}$. Furthermore, the students were unable to process important changes in patients and perform appropriate nursing interventions. Simulation can help reinforce theory in a controlled environment without harm to patients.

A simulation study revealed that students needed improvement in critical thinking skills ${ }^{[8]}$. In simulation scenarios, students were actually prepared to take the wrong patient to the operating room and willing to admit a preoperative patient in a room with a patient who had methicillin resistant staphylococcus aureas ${ }^{[8]}$. Not only did simulation prevent these hazards to patient safety, but helped students develop critical decision-making skills to prioritize and avoid errors. Another study to test students' ability to manage medication safety and adverse events used avatars. The use of avatars in virtual simulation is a different type of simulated experience that facilitates role-play to improve interpersonal skills among senior level nursing students ${ }^{[7]}$. It helped prepare them for situations they will encounter on the job.

To safely manage care, nurses must demonstrate effective communication, delegation, and critical decision-making skills. These studies revealed that had these students been faced with the same situation in the clinical setting, patients would be at risk and possibly harmed. Simulation facilitated learning in a way that prevented such misfortune.

Students who attended simulation as the first $25 \%$ of their clinical experiences attained clinical performance competency more quickly than their counterparts ${ }^{[11]}$. Simulation also improved their clinical performance in leadership and management skills ${ }^{[11]}$. Another study found that students who were taught leadership competencies using standardized patient scenarios reported enhancement of their ability to apply leadership principles ${ }^{[13]}$. Again, the controlled environment supported student learning, while maintaining patient safety. "Simulation translates into the clinical setting and has positive patient safety outcomes" ${ }^{[12]}$. Students in leadership simulation with debriefing reported the experience was well organized, prompted realistic expectations, and increased their understanding ${ }^{[10]}$. Furthermore, they reported that the experience increased their understanding of prioritizing \& delegating care ${ }^{[10]}$. Seventy-eight percent reported "more confidence in ability to work as a team" and "more confidence in prioritizing and delegating care" ${ }^{[10]}$. It is not possible to maintain control of scenarios and outcomes in a live patient care situation. Building simulated experiences in which students can practice their decision-making, critical thinking, and an overall sense of their role as a nurse, improves confidence. Students reported that their simulation encounter helped and decreased their level of stress associated with clinical performance ${ }^{[15]}$. These studies have valuable data for faculty to implement in helping students communicate with others and collaborate with team members. There was improvement in teamwork and collaboration in an interprofessional group of nursing and medical students ${ }^{[9]}$. Simulation has shown efficacy in student demonstration of effective communication across disciplines to successfully acclimate to their new role as nurses.

To be effective in their new nursing roles, students must learn to safely manage complex patient situations and enhance self-confidence. Simulation participants reported they were well prepared to confidently care for critically ill patients ${ }^{[17]}$. 
Computer-based simulation also improved student's clinical judgment ${ }^{[15]}$. Overall, the literature reflects that simulation can be a very effective way of helping nursing students gain readiness for practice.

\section{The pedagogy of simulation in BSN leadership and management}

Current evidence suggests that simulation provides the best environment outside of actual clinical experiences in which students can practice realistic patient care and be more actively engaged in teaching and learning simultaneously. Simulation also provides opportunities for students to build confidence and enter nursing practice ready to practice nursing leadership.

Relevant theories to support this pedagogy of simulation for positive student learning outcomes exist. They include Behavioral learning theory, Cognitive learning theory, Cognitive load theory, and Stress inoculation theory.

Behavioral learning theory defines learning as "the relatively permanent change in behavior brought about as a result of experience or practice" ${ }^{[19]}$. Learning is an internal occurrence, but is not defined as such until the student displays an appropriate outward behavior that reflects the learning. The goal in behavioral theory is observable change in the learner's behavior. In the case of nursing students, the goal is the development of critical thinking and problem solving skills through application of theory in simulation. The instructor guides the learning process and reinforces desired change through directed reflection and feedback in the debriefing phase of simulation training. The behavior change is then transferable to various clinical settings of the student’s personal practice.

Like Behavioral learning theory, Cognitive learning theory has a crucial place in sustaining student knowledge through simulation. Cognitive learning theory suggests that, through active engagement, individuals form learning using internal mental activity ${ }^{[20]}$. Essentially, the faculty guides the student to using thinking, in this case critical thinking, to learn. Individuals observe, categorize, and use sensory input to make generalizations that form knowledge. Cognitive learning includes accommodation, assimilation, and equilibration ${ }^{[20]}$. The goals of Cognitive learning theory in simulation are to 1) help students use simulated scenarios as a means to transition theory to application (accommodation); 2) facilitate students' role-play of scenarios to help them merge new knowledge into cognitive mindsets (assimilation); and 3) lead students to find balance in previous knowledge with simulated activities to master new material (equilibration). Cognitive learning is cumulative and simulation helps students build on previous knowledge gained in didactic portions of the course. A strategy to build cognitive learning is assigning pre-simulation reading or videos that can be reinforced through interaction in simulation. The instructor provides learning scenarios to guide the students to connect new concepts to theory learned in the classroom with simulated clinical situations. Another important strategy is encouraging learners in simulation to discover solutions via appropriate actions that require critical thinking and problem solving. The student acquires "usable knowledge and problem-solving know-how" ${ }^{[21]}$. The instructor examines the students' thought processes to reaching the desired decisions that guide their actions.

Faculty must be careful to provide the appropriate amount of learning in given intervals. Cognitive Load theory suggests that short-term memory or working memory can only hold about 3-5 information units ${ }^{[22]}$. All information (including visual, auditory or spoken) increases cognitive load and actually slows learning ${ }^{[22]}$. To keep the cognitive load low during the simulated learning process in the leadership course, faculty should keep the scenario as basic as is possible to sufficiently deliver the content. For example, when the goal is teaching delegation, faculty should avoid advanced clinical information, such as IV drip rates and complete medications listing in a scenario and simply lay out the task in which the student should delegate. Simulation scenarios should be appropriate to the learner. It should help the student master the task or skillset at hand to build confidence and advance to higher level learning and critical thinking. As the student advances and demonstrates progressive skills, scenarios should be advanced likewise. If the student has experienced simulation in other nursing courses, the leadership scenarios can be more complex to ensure the learner is continually intrigued. 
A final theory that is important in teaching simulation is Stress Inoculation theory. This theory has a basis in cognitive behavioral theory. It is used to teach high stress and risk situations such as a sudden change in a patient situation or suddenly experiencing unexpected aggressive behavior from a peer. Stress Inoculation Theory purports that when learners practice these stressful situations in simulation they would probably react more appropriately as a result of being prepared through practice ${ }^{[23]}$. Guiding students through these stressful situations in a controlled environment where opportunities exist to stop and start again, without harm or threat to patient safety, is invaluable.

Each of these theories should be taken into account when developing a simulation experience. Additionally, faculty should integrate these theories into the education process. This process focuses on an assessment that is completed to plan and implement teaching based on the students' learning needs, readiness to learn and motivation to learn. Throughout this process, evaluation must be formative, as well as summative, to meet students' needs.

Faculty must use information gathered in the assessment to develop a teaching plan that is based on specific behavioral outcomes that nursing students will need as new professional nurses. These behaviors must reinforce didactic theory taught in Nursing Leadership and Management courses. Prior to implementation, faculty should help prepare students for learning with pre-simulation preparation. Assigned reading or video lectures such as Tegrity ${ }^{\circledR} 24$ or Adobe Connect ${ }^{\circledR} 25$ can be used to help the students achieve pre-simulation preparation.

Implementation involves actually performing the art of teaching. Simulation should include real-life situations that students will encounter as nurses. They should be as real as possible. Diversity, psychosocial issues, multicultural concerns, etc. should be included where appropriate. Students should be taught to respect the scenario as if it were a real life situation. Identification with the role-play of the scenarios is improved when signs are made that designate the role that he/she and fellow classmates are playing in the simulation. Faculty should seek to help students envision themselves in actual clinical situations.

Faculty follow a scripted plan to help the students act out specific aspects of nursing leadership and management that other students have reported problematic in role transitions. Using a template helps faculty remember information that may be otherwise easily forgotten. Templates also help standardize scenarios among faculty and courses. Templates should list success criteria and actions to be taken by the student to achieve success. Faculty should be prepared with a designated area or plan that students who may be stuck or unable to decide the next action can have a time-out for consultation with faculty and then resume the scenario. This should be well understood by the students before the scenarios begin. Such measures will lesson student anxiety and help avoid cognitive overload ${ }^{[22]}$. Learning occurs when the student demonstrates the expected behavior, is able to relate to course theory, and can accurately describe the critical thought process used in decision making.

Lastly, the evaluation determines whether the behavior change has occurred. Change in students' knowledge and skills should be evaluated to ensure the desired outcome has occurred. Many methods will support the evaluation process but should include self-evaluation, peer-evaluation, and faculty evaluation. Time for debriefing should be built into each scenario. Faculty should take every opportunity to facilitate learning throughout the simulation process; remembering that students in simulation learn through participating, observing, and debriefing ${ }^{[26]}$. After debriefing, scenarios can be repeated and the students provided an opportunity to correct errors or omissions that may have occurred in the first-run. This also provides an opportunity for scenarios to always end on a good note instead of a less effective one that leaves the learner with a sense of failure.

Other ways of quantifying student learning may include pre-test/post-test and/or comparison of Assessment Technologies Institute ${ }^{\circledR 27}$ (ATI) or other National Council Licensure Examination for Registered Nurses (NCLEX-RN)3 style evaluation testing. The evaluation aids faculty in determining necessary modifications to the education plan. Faculty must assess, plan, implement, and evaluate throughout the education process. Phases are overlapping and when student learning is not achieved in any process, faculty should reassess and adjust the plan accordingly. 
The proposed teaching strategy incorporates pedagogy associated with implementation of simulation in a BSN leadership and management course through four scenarios. A brief synopsis of each scenario follows. Detailed scenarios are included in tables 1-4 and reflect topic, learning objectives, associated textbook reading, scenario description, student success criteria, and space for evaluator's notes.

Table 1. Patient Safety

\begin{tabular}{|c|c|c|}
\hline \multirow[t]{2}{*}{$\begin{array}{l}\text { Leadership Simulation } \\
\text { Learning Plan }\end{array}$} & General Objectives & $\begin{array}{l}\text { Through simulation the student will: } \\
\text { - } \quad \text { Identify threats to patient safety. } \\
\text { - } \quad \text { Remove or lesson threat to patient. } \\
\text { - } \quad \text { Implement patient safety strategies. }\end{array}$ \\
\hline & Topic & Patient Safety \\
\hline Textbook Pre-simulation Reading ${ }^{[29]}$ & \multicolumn{2}{|c|}{$\begin{array}{l}\text { Chapter } 2 \\
\text { Patient Safety } \\
\text { Content } \\
\text { Institute of Medicine Reports on Quality, Agency for Healthcare Research and Quality, } \\
\text { Meaning for leading and managing in nursing }\end{array}$} \\
\hline Scenario \#1 - Patient Safety & \multicolumn{2}{|c|}{$\begin{array}{l}\text { Student \#1 - You are a new graduate nurse working on a surgical unit. You have three } \\
\text { (3) post-operative day } 1 \text { patients and one of them, Mrs. Brown, has had significant } \\
\text { changes in her vital signs that lead you to believe she may have internal } \\
\text { hemorrhage. Dr. Jones, also known as Mr. Scrooge by the nurses on the unit, is on call } \\
\text { tonight. He is always mean to nurses and belittles them when they awaken him in the } \\
\text { middle of the night. You need to keep your patient safe and recognize that not getting } \\
\text { help may result in serious detriment to your patient. } \\
\text { Student \#2 - You are the charge nurse on the unit, Dale. You should be prepared in the } \\
\text { even Student \#1 brings this situation to you. } \\
\text { Student \#3 - You are Dr. Jones. Your role is to make communication with Students \#1 } \\
\text { and \#2 extremely difficult. You should express great hesitancy about coming to assess } \\
\text { this patient. } \\
\text { Moderate Fidelity Manikin settings: The manikin begins with normal vital signs. After } \\
\text { the nurse receives report she notices changes in vital signs, the patient is restless, and } \\
\text { exhibits verbal expressions of fear of eminent death. }\end{array}$} \\
\hline Students Success Criteria & \multicolumn{2}{|c|}{$\begin{array}{l}\text { (1) Identify threats to patient safety. } \\
\text { (2) Act quickly to remove or lesson threat to safety. } \\
\text { (3) Evaluate risks that may have led to patient harm and identify ways to avoid in } \\
\text { future. } \\
\text { (4) Communicate with Dr. Jones using situation, background, assessment, and } \\
\text { recommendation (SBAR) communication }\end{array}$} \\
\hline Instructor's Evaluation Notes & \multicolumn{2}{|c|}{$\begin{array}{l}\text { The student receives } 1 \text { point for each success criterion. Maximum points }-4 \text {. } \\
\text { Comments }\end{array}$} \\
\hline
\end{tabular}

\section{Brief synopsis of simulation scenarios}

The learning scenarios have been placed in tables immediately following this section. These scenarios are to be completed in one four-hour simulation session (50 minutes per scenario with 10 minute breaks after each). Four faculty members are needed to facilitate the simulated scenarios. Faculty can opt to run the four scenarios consecutively and have students rotate to the faculty who will manage a particular topic. In this option, each faculty facilitates and evaluates four groups of students for the same scenario. Conversely one faculty member can facilitate each scenario with a single group of students. In this second option, four faculty members evaluate a single group of students in each of the simulated scenarios. SIMman ${ }^{\circledR}$ ("a realistic, full-body adult, wireless patient simulator") ${ }^{[28]}$ may not always be needed in carrying out simulation scenarios in Leadership and Nursing Management; however, recording equipment with debriefing capabilities 
is critical in helping the students play out leadership situations and then review and discuss their decisions and actions with faculty.

Table 2. Problem Solving

\begin{tabular}{|c|c|c|}
\hline \multirow[t]{2}{*}{$\begin{array}{l}\text { Leadership Simulation } \\
\text { Learning Plan }\end{array}$} & General Objectives & 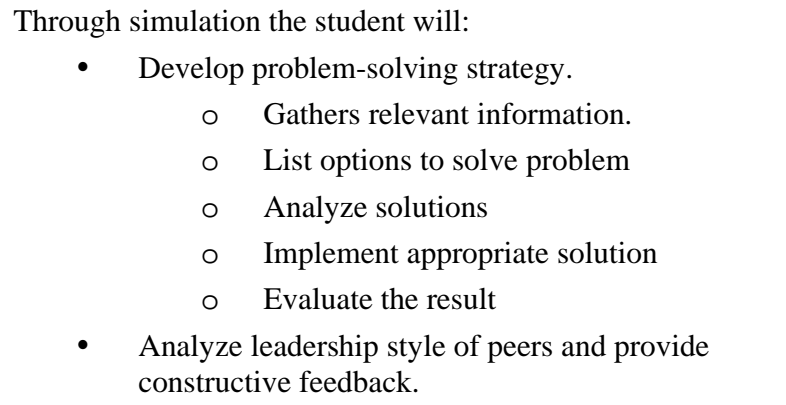 \\
\hline & Topic & Problem Solving \\
\hline Textbook Pre-simulation Reading ${ }^{[29]}$ & \multicolumn{2}{|c|}{$\begin{array}{l}\text { Chapter } 6 \\
\text { Making Decisions and Solving Problems } \\
\text { Content } \\
\text { Decision models, styles, and factors affecting decision making } \\
\text { Group decision making (advantages, challenges, and strategies) } \\
\text { Decision-making tools } \\
\text { Problem-solving process } \\
\text { Chapter 26: Delegation: An Art of Professional Practice } \\
\text { Content } \\
\text { Charge nurses }\end{array}$} \\
\hline Scenario \#2 - Problem Solving & \multicolumn{2}{|c|}{$\begin{array}{l}\text { Student \#1 - You are Terry, the day shift charge nurse on a 15-bed surgical unit. You } \\
\text { have been out of school } 6 \text { months but because of your leadership abilities, you have been } \\
\text { oriented to charge nurse. This is your second day since charge orientation. You are } \\
\text { preparing to make the assignment for the night shift and note that Brenda is working. } \\
\text { She constantly complains about her assignments and it makes you nervous to assign } \\
\text { complex patients to her. Brenda is scheduled to work with Joey, a new graduate nurse, } \\
\text { and Alexis, an experienced nurse who consistently volunteers to help others with their } \\
\text { patient load when she is not busy. There are } 3 \text { patients with high acuity on the unit and } \\
\text { reason tells you that you should assign one to each nurse but you fear the response you } \\
\text { will receive from Brenda. } \\
\text { Student \#2 - You are Brenda. Your roll is to complain about the assignment regardless } \\
\text { of what Student \#1 (the charge nurse) does. } \\
\text { Student \#3 - You are Alexis. You are ambiguous about the assignment to student \#1, but } \\
\text { complain about the lack of fairness on the unit to student \#4 (Joey). } \\
\text { Student \#4 - You are Joey. Your roll is to point out the unfairness of the assignment if } \\
\text { Brenda does not have one of the high acuity patients and you have two of them }\end{array}$} \\
\hline Students Success Criteria & \multicolumn{2}{|c|}{$\begin{array}{l}\text { (1) Complete thorough assessment of situation. } \\
\text { (2) Identify options to solving the problem. } \\
\text { (3) Identify positives and negatives of each solution. } \\
\text { (4) Prioritize and implement best solution } \\
\text { (5) Discuss Student \#1's leadership style and provides feedback in debriefing. }\end{array}$} \\
\hline Instructor's Evaluation Notes & \multicolumn{2}{|c|}{$\begin{array}{l}\text { The student receives } 1 \text { point for each success criterion. Maximum points - } 5 \\
\text { Comments }\end{array}$} \\
\hline
\end{tabular}


Table 3. Conflict Resolution

\begin{tabular}{|c|c|c|}
\hline \multirow[t]{2}{*}{$\begin{array}{l}\text { Leadership Simulation } \\
\text { Learning Plan }\end{array}$} & General Objectives & $\begin{array}{l}\text { Through simulation the student will: } \\
\qquad \begin{aligned} & \text { - Resolve conflict using a systematic approach: } \\
& \text { o Analyze a situation using the conflict } \\
& \text { process } \\
& \text { o } \text { Determine the cause of conflict } \\
& 0 \text { Evaluate } 5 \text { available approaches and } \\
& \text { implement }\end{aligned}\end{array}$ \\
\hline & Topic & Conflict Resolution \\
\hline Textbook Pre-simulation Reading ${ }^{[29]}$ & \multicolumn{2}{|c|}{$\begin{array}{l}\text { Chapter 23: } \\
\text { Conflict: The Cutting Edge of Change } \\
\text { Content } \\
\text { Types, Stages, and Categories of conflict } \\
\text { Modes of conflict resolution - (Avoiding, Accommodating, Competing, Compromising, } \\
\text { or Collaborating) }\end{array}$} \\
\hline Scenario \#3 - Conflict Resolution & \multicolumn{2}{|c|}{$\begin{array}{l}\text { Student \#1 - You are Suzie, a new professional nurse who has been asked by her } \\
\text { Manager to help implement a new project on the unit. She has seen your ability to } \\
\text { influence others and would like you to be a part of this team. The hospital's Quality } \\
\text { Division has recently completed an evidence-based practice review of hand hygiene and } \\
\text { has decided to change to a waterless hand sanitizer solution dispenser. You have } \\
\text { developed an in-service to introduce the staff to the new product. However, as you're } \\
\text { setting up your PowerPoint, you hear mumbling in the back of the room. It is disruptive } \\
\text { to the point that you can't get the room quieted enough to begin your presentation. } \\
\text { Student \#2 - You are Mary, a nurse with much more experience on the unit. In fact, you } \\
\text { have been there for } 10 \text { years and have one year toward your Master's Degree. You don’t } \\
\text { understand why you were not selected. And you want to make sure everyone knows your } \\
\text { displeasure. } \\
\text { Student \#3 - You are Ed, another new professional nurse. You disagree with the new } \\
\text { dispenser because you remember reading a long time ago that soap and water is the best } \\
\text { way to kill germs. You are determined you are one, not going to do it; and two, going to } \\
\text { make sure everyone knows what you learned about hand washing. }\end{array}$} \\
\hline Students Success Criteria & \multicolumn{2}{|c|}{$\begin{array}{l}\text { (1) Assess personal ways of resolving conflict. } \\
\text { (2) Identify four stages of conflict in clinical scenario. } \\
\text { (3) Evaluate and implement appropriate mode of conflict resolution. }\end{array}$} \\
\hline Instructor's Evaluation Notes & \multicolumn{2}{|c|}{$\begin{array}{l}\text { The student receives } 1 \text { point for each success criterion. Maximum points }-3 \\
\text { Comments }\end{array}$} \\
\hline
\end{tabular}

The following four topics are presented as an initial guide to implement simulation or role-playing in a BSN Leadership and Management course. Other pertinent topics should be developed and integrated into the course. It is, however, recommended that no more that four topics be presented in a single session, as the students are required to complete pre-simulation reading to be able to demonstrate and synthesize information in a usable manner.

Although each scenario has a primary focus, students are required to integrate many leadership and management skills to effectively complete the nursing care required by the scenarios. They will also be required to use the Quality Safety and Education for Nurses (QSEN) ${ }^{[1]}$ competencies throughout the scenarios to successfully reach suitable outcomes for their patients, peers, and themselves.

\section{Scenario \# 1 - Patient safety}

In the patient safety scenario a student is faced with contacting a doctor who has a reputation of not wanting to be awakened during the night. The student must demonstrate the ability to identify threats to patient safety and communicate effectively with the physician team member to maintain patient safety. This scenario can be modified to add additional 
roles (i.e. unlicensed assistive personnel, a secondary nurse, etc) depending on the number of students in simulation. This scenario can even be modified to have the patient's situation decline to the point of requiring emergency fluid resuscitation. Many themes of professional nursing are embedded in this exercise. Included are patient-centered care, advocacy, communication techniques, teamwork, collaboration, use of evidence-based practice, and patient safety.

Table 4. Delegation

\begin{tabular}{|c|c|c|}
\hline \multirow[t]{2}{*}{$\begin{array}{l}\text { Leadership Simulation } \\
\text { Learning Plan }\end{array}$} & General Objectives & $\begin{array}{l}\text { Through simulation the student will: } \\
\text { - } \quad \text { Determine appropriate tasks to delegate. } \\
\text { - } \\
\text { - } \\
\text { Delect the appropriate delegatee. } \\
\text { board of nursing. } \\
\text { - Supervise the delegated act. } \\
\text { Maintain accountability for the delegated act. }\end{array}$ \\
\hline & Topic & Delegation \\
\hline Textbook Pre-simulation Reading ${ }^{[29]}$ & \multicolumn{2}{|c|}{$\begin{array}{l}\text { Chapter 26: Delegation: An Art of Professional Practice } \\
\text { Content } \\
\text { A framework for delegation } \\
\text { Assignment versus delegation } \\
\text { The importance of delegation } \\
\text { Legal authority to delegate } \\
\text { Delegation decision making process and challenges. }\end{array}$} \\
\hline Scenario \#4 - Conflict Resolution & \multicolumn{2}{|c|}{$\begin{array}{l}\text { Student \#1 - You are Sylvia, a new professional nurse who has been out of working on } \\
\text { the surgical unit for about } 5 \text { months now. You arrived at work this morning to learn that } \\
\text { you are working with a Clinical Associate (CA), Brittany, who always gives you a hard } \\
\text { time. You have been so frustrated with her not wanting to help with patient care that you } \\
\text { have frequently decided to just do it yourself. However, today you learn that the unit is } \\
\text { short a nurse and there is absolutely no way you can do it all. Brittany has been working } \\
\text { as a CA for about } 5 \text { years now and knows the unit really well. She could be an asset to } \\
\text { you but you're not sure how to delegate to her so that she does what you're asking. You } \\
\text { are caring for Ms. Jones, who has the following orders: } \\
\text { - Admit to } 6 \text { West, s/p open colectomy. Infuse normal saline at } 100 \mathrm{ml} / \text { hour } \\
\text { - NPO except medications } \\
\text { - Lopressor 100mg po daily } \\
\text { - Pepcid 20mg IV daily } \\
\text { - Reinforce surgical dressing every four hours as needed } \\
\text { - } \quad \text { Vital signs every four hours } \\
\text { Student \#2 - LPN, Lee - Complete tasks as delegated (even if outside of scope of } \\
\text { practice). } \\
\text { Student \#3 - CA, Brittany. You should respond to every request with an attitude and/or } \\
\text { complaints. }\end{array}$} \\
\hline Students Success Criteria & $\begin{array}{l}\text { (1) Communicates } \\
\text { (2) Complete adm } \\
\text { (3) Complete adm } \\
\text { (4) Delegate LPN } \\
\text { (5) Delegate po m } \\
\text { (6) Delegate vital } \\
\text { (7) Delegate input } \\
\text { (8) Reinforce surg }\end{array}$ & $\begin{array}{l}\text { ctively with the Delegatee. } \\
\text { n physical assessment. } \\
\text { n written assessment. } \\
\text { ng new bag of fluid (per hospital policy) } \\
\text { tions to LPN. } \\
\text { to CA. } \\
\text { ut to CA. } \\
\text { dressing with each assessment as needed. }\end{array}$ \\
\hline Instructor's Evaluation Notes & $\begin{array}{l}\text { The student receive } \\
\text { Comments }\end{array}$ & oint for each success criterion. Maximum points - 8 \\
\hline
\end{tabular}




\section{Scenario \# 2 - Problem solving}

The scenario of the new graduate who soon finds herself in the charge nurse role is one that happens often in nursing today. New graduates are faced with the challenge of fitting in and making others happy to be accepted in the nursing profession. Learning to eliminate the fear of being rejected in favor of acting in the best interest of patient safety is a critical lesson that warrants practice before it is actually experienced at work. Additionally, role-playing through simulation affords them the opportunity to act out their fears and learn the appropriate way of dealing with such issues. Helping the students recognize unprofessional behaviors and develop management strategies early can help them better transition into their new roles as nurses and often early, charge nurse roles.

\section{Scenario \# 3 - Conflict resolution}

Suzie is a new professional nurse who has been asked to serve on a Task Force to implement a new hand sanitizer dispenser on her unit. She quickly learns that not everyone is as happy about her being selected for this role. In this scenario, the student must use a systematic approach to resolve conflict on the nursing unit. It is necessary that she completes an analysis of the situation, determines the cause of the conflict, evaluates available options, and implements an appropriate option. The student should explore the stages of conflict (Frustration, Conceptualization, Action, and Outcomes) and categorize the conflict. The student should be able to correctly identify the mode of resolution implemented (Avoiding, Accommodation, Competing, Compromising, or Collaborating). The student may even have to involve the Nurse Manager since this initiative is mandatory hospital-wide. The debriefing will allow all students involved to reflect on their thoughts and feelings during the scenario. Realizing that conflict is never easy, using this systematic approach in simulation will allow students an opportunity to be prepared for conflict when it arises in their professional practice.

\section{Scenario \# 4 - delegation}

In the delegation scenario, Sylvia, is confronted with her fear of delegating to a Clinical Associate (CA) who makes delegating quite difficult. Sylvia has to face her demons and find a way to move forward in her young professional nursing career. She must select the appropriate tasks to delegate and hold her delegatee accountable to complete the task. Sylvia's communications skills are also required to effectively assign tasks to the delegatee in the scenario.

\section{Conclusion}

Simulation can have many faces and can be adapted to facilitate student learning needs. The key is appropriate scenarios with theory-based pedagogy woven throughout. Schools of nursing can vary experiences from high fidelity simulation to simple role-play of important leadership scenarios and provide benefit to students who are at the cusp of entering clinical practice. The use of avatars in a virtual simulation experience may be useful in places where simulation centers are unavailable ${ }^{[3]}$. The goal of the role-play was to improve interpersonal skills among senior level nursing students. The ultimate goal of integrating simulation in leadership courses is to use appropriate learning scenarios that will prepare the student for the situations they will encounter on the job.

Despite it being reasonable to expect that pedagogy can be translated to learning environments such as simulation, the void of pedagogy in simulation today was noted ${ }^{[8]}$. Although current evidence is scant, it has shown that simulation in leadership and management BSN courses allows for the use of a controlled environment to promote patient safety, decrease medical errors, and improve student confidence. Educators should continue integrating simulation into leadership courses and publish results. These data should reflect the effect of simulated learning on NCLEX or ATI results; improvement of student perception of transitioning to care at the bedside; faculty's quantitative measurement of student success in simulation; and faculty perception of student learning. Furthermore, researchers are called to complete inquiries of the efficacy of simulated learning experiences in nursing leadership and management courses. Both of these activities are important to building a stronger body of evidence upon which future curricula can be designed. 


\section{References}

[1] Quality and Safety Education for Nursing (n.d.), website review. Available from: http://www.qsen.org/competencies.php

[2] American Association of Colleges of Nursing. The essentials of baccalaureate education for professional nursing practice. 2011; Washington, DC: Author

[3] National Council of State Boards of Nursing. 2013. NCLEX-RN Examination: Test plan for the national council licensure examination for registered nurses. Available from: https://www.ncsbn.org/1287.htm

[4] National League for Nursing (n.d.) Website review of simulation and technology. Available from: https://www.nln.org/facultyprograms/simulation_tech.htm.

[5] Cronenwett LR. The future of nursing education: summary and conclusions. National Academy of Sciences. Available from: www.iom.edu/ /media/Files/Activity\%20Files/Workforce/Nursing/Future\%20of\%20Nursing\%20Education.pdf

[6] Scheckel, M. Nursing education: Past, present, future. In G. Roux and J. Halstead (Eds.), Issues and trends in nursing. $2009: 27-55$. Sudbury, Massachusetts: Jones and Bartlett.

[7] Aebersold, M, Tschannen D, and Bathish M. Innovative simulation strategies in education. Nursing Research and Practice, 2012; Article ID 765212, 7 pages. http://dx.doi.org/10.1155/2012/765212

[8] Schultz MA, Shinnick, MA, and Judson, LH. Learning from mistakes in a simulated nursing leadership laboratory. Computers, Informatics, Nursing. 2012; 30(9): 456-62. http://dx.doi.org/10.1097/NXN.0b013e3182573aaf.

[9] Hobgood C, Sherwood G, Frush K, et al. Teamwork training with nursing and medical students: does the method matter? Results of an inter-institutional, interdisciplinary collaboration. Quality and Safety in Health Care. 2010; 19: 1-6.

[10] Kaplan, B. and Ura, D. Use of multiple patient simulators to enhance prioritizing and delegating skills for senior nursing students. Journal of Nursing Education. 2010; 49(7): 371-377. PMid:20411859 http://dx.doi.org/10.3928/01484834-20100331-07

[11] Meyer M, Connors H, Hou Q, and Gajewski B. The effect of simulation on clinical performance: a junior nursing student clinical comparison study. Simulation in Healthcare: The Journal of the Society for Simulation in Healthcare. 2011; 6(5): $269-277$. http://dx.doi.org/10.1097/SIH.0b013e318223a048

[12] Schaefer JJ, Vanderbilt AA, Cason CL, Bauman EB, Glavin RJ, Lee FW, and Navedo DD. Literature review: instructional design and pedagogy science in healthcare simulation. Simulation in Healthcare. 2011; 6(7): S30-S41. PMid:21817861 http://dx.doi.org/10.1097/SIH.0b013e31822237b4

[13] Sharpnack PA, Goliat L, and Rogers K. Using standardized patients to teach leadership compentencies. Clinical Simulation in Nursing, In Press Corrected Proof. 2011: e1-e8.

[14] Walton J, Chute E and Ball L. Negotiating the role of the professional nurse: The pedagogy of simulation: A grounded theory study. Journal of Professional Nursing. 2011; 5(27); 299-310. PMid:21925463 http://dx.doi.org/10.1016/j.profnurs.2011.04.005

[15] Weatherspoon DL and Wyatt TH. Testing computer-based simulation to enhance clinical judgment skills in senior nursing students. Nursing Clinics of North America. 2011; 47(4): 481-91. http://dx.doi.org/10.1016/j.cnur.2012.07.002.

[16] Cardoza MP and Hood PA. Comparative study of baccalaureate nursing student self-efficacy before and after simulation. Computer Informatics Nursing. 2012; 30 (3): 142-7. PMid:22080746 http://dx.doi.org/10.1097/NCN.0b013e3182388936

[17] Kaddoura, M.A. New graduate nurses' perceptions of the effects of clinical simulation on their critical thinking, learning, and confidence. Journal of Continuing Education in Nursing. 2010; 41(11): 506-516. http://dx.doi.org/10.3928/00220124-20100701-02

[18] Reising DL, Carr DE, Shea RA, and King JM. Comparison of communication outcomes in traditional versus simulation strategies in nursing and medical students. Nursing Education Perspective. 2011; (5): 323-7. PMid:22029245 http://dx.doi.org/10.5480/1536-5026-32.5.323

[19] Huitt, W., \& Hummel, J. 2006. An overview of the behavioral perspective. Educational Psychology Interactive. Valdosta, GA: Valdosta State University. Retrieved February 18, 2013. Available from: http://www.edpsycinteractive.org/topics/behavior/behsys.html

[20] Shunk, D.H. (2012). Cognitive learning theories in: Learning theories: An educational perspective, (6th Ed.). Pearson: Bosn.

[21] Ozuah PO. First, there was pedagogy and then came andragogy. Einstein Journal of Biological Medicine. 2005 ; (21): 83-87.

[22] Merrienboer, J.J. and Sweller, J. Cognitive load theory in health professional education: Design principles and strategies. Medical Education. 2010; 44: 85-93. http://dx.doi.org/10.1111/j.1365-2923-2009.03498.x

[23] Meichenbaum, D. Stress inoculation training for coping with stressors. The Clinical Psychologist. 1996; 49: 4-7. Available from: http://www.apa.org/divisions/div12/rev_est/sit_stress.html

[24] McGraw Hill Tegrity website review. Accessed February 18, 2013. Available from: http://www.tegrity.com/about. 
[25] Adobeconnect website review. Accessed online February 18, 2013. Available from: http://success.adobe.com/content/en/na/programs/products/connect/1211-web-conferences.html?skwcid=TC|22191|adobe\%20co nnect||S|e|21117383062andef_id=GYxPOX0IeScAAEMd:20130218164557:s

[26] Rothgeb, M.K. Creating a nursing simulation laboratory: A literature review. Journal of Nursing Education. 2008; 47(11): 489-494. ISSN: 0148-4834 PMid:19010046 http://dx.doi.org/10.3928/01484834-20081101-06

[27] Assessment Technologies Institute ${ }^{\circledR}$ website review. Accessed online February 18, 2013. Available from: https://www.atitesting.com/Home.aspx.

[28] Laerdal website review. Accessed online February 18, 2013. Available from: http://www.laerdal.com/doc/86/SimMan.

[29] Yoder-Wise PS. Leading and managing in nursing (5h ed.). St. Louis: Mosby. 2007; (ISBN \# 978-0-323-06977-9)

[30] McGrath, M., Lyng, C. and Hourican, S. From simulation lab to the ward: Preparing 4th year nursing students for the role of staff nurse. Clinical Simulation in Nursing. 2012; 8(7): e265-272. http://dx.doi.org/10.1016/j.ecns.2010.10.003

[31] Piscotty, R., Grobbel, C., \& Huey-Ming, T. Integrating Quality and Safety Competencies into Undergraduate Nursing Using Student-Designed Simulation. Journal Of Nursing Education. 2011; 50(8): 429-436. http://dx.doi.org/10.3928/01484834-20110429-04

[32] Simones, J., Wilcox, J., Scott, K., Goeden, D., Copley, D., Doetkott, R., and Kippley, M. Collaborative simulation project to teach scope of practice. Journal of Nursing Education. 2010; 49(4): 190-197. PMid:20055331

http://dx.doi.org/10.3928/01484834-20091217-01 